To the Editors:

\title{
Chronic hypernatraemia due to osmoreceptor dysfunction
}

Plasma osmolality is regulated by the interaction of the kidneys, arginine vasopressin (AVP), and thirst - the last two being stimulated by hypothalamic osmoreceptor signals. Osmoreceptor dysfunction may cause hypernatraemia, hyperviscosity and considerable morbidity, and may be associated with other endocrine dysfunction $[1,2]$. We report two patients with chronic hypernatraemia and osmoreceptor dysfunction.

\section{Patient 1}

A middle-aged, previously healthy, asymptomatic man on no medication, was found to have chronic hypernatraemia. Clinical examination was unremarkable. His serum sodium varied between $146-152 \mathrm{mmol} / \mathrm{l}$. At the conclusion of a standard water deprivation test, urine and serum osmolalities were 512 and $308 \mathrm{mosm} / \mathrm{kg}$, urine output was $45 \mathrm{ml} /$ hour, and plasma AVP was $0.15 \mathrm{pg} / \mathrm{ml}$ (low). Urine osmolality increased to $812 \mathrm{mosm} / \mathrm{kg}$ after DDAVP, suggesting partial cranial diabetes insipidus (CDI). He had no thirst during or after the test (adipsic). A short Synacthen test (SST) was sub-optimal. MRI scans revealed a small pituitary, partially empty sella and an absent posterior pituitary "bright signal".

\section{Patient 2}

A middle-aged woman with diabetes mellitus $\left(\mathrm{HbA}_{1 \mathrm{C}}\right.$ $6.5 \%$ ), on appropriate medication, had troublesome thirst, polyuria and nocturia. She was obese but otherwise unremarkable. Her serum sodium was $146-149 \mathrm{mmol} / \mathrm{l}$. The water deprivation test, SST and MRI scans of the pituitary were normal.
Screening tests for hyperaldosteronism, hypercortisolism and pituitary dysfunction were normal in both patients. A hypertonic saline infusion test was done [3].

Both patients failed to increase AVP secretion at expected levels of serum sodium and osmolality i.e. their osmoreceptor was reset to a higher threshold. In addition patient 1 was adipsic during and after the test but patient 2 was thirsty and drank $700 \mathrm{ml}$ of water.

These patients had an upward resetting of their hypothalamic osmoreceptor. Patient 1 also had partial CDI and the adipsic syndrome, unlike patient 2 who had normal endocrine function and thirst. The osmoreceptor functions as a "sensor" for both AVP secretion and thirst. Diseases affecting it may cause perturbations of both these elements (patient 1) or affect one independent of the other eg. altered threshold for AVP release with preserved thirst (patient 2). AVP synthesising neurones may also be affected in disease involving the osmoreceptor because of their physical proximity, resulting in complete or partial CDI as in patient 1 . Patient 1 is on a fixed fluid intake with close monitoring of his electrolytes and weight. His adipsia places him at high risk of hypernatraemia and hyperviscosity after hypotonic fluid loss and lack of access to water. Patient 2 is on $10 \mu \mathrm{g}$ of DDAVP at night. Both are well, asymptomatic and normonatraemic.

The contribution of the hypothalamic osmoreceptor and thirst sensation to the regulation of water homeostasis is increasingly recognised [4]. Investigation of chronic hypernatraemia is important in identifying subtle abnormalities in these regulatory mechanisms and avoiding potentially significant morbidity.

Table 1. Hypertonic saline infusion test

\begin{tabular}{ccccc}
\hline & $\begin{array}{c}\text { Time } \\
(\mathrm{min})\end{array}$ & $\begin{array}{c}\text { Serum sodium } \\
(\text { mmol/l) }\end{array}$ & $\begin{array}{c}\text { Serum osmolality } \\
(\text { mosm } / \mathrm{kg})\end{array}$ & $\begin{array}{c}\text { Plasma AVP } \\
(\mathrm{pg} / \mathrm{ml})\end{array}$ \\
\hline \multirow{2}{*}{ Patient 1 } & 0 & 146 & 307 & 0.23 \\
& 30 & 147 & 312 & 0.29 \\
& 60 & 150 & 318 & 0.53 \\
& 90 & 152 & 321 & 0.84 \\
& 120 & 154 & 327 & 1.83 \\
\hline Patient 2 & 0 & 144 & 303 & 0.5 \\
& 30 & 147 & 315 & 1.6 \\
& 60 & 147 & 315 & 2.1 \\
& 90 & 150 & 319 & - \\
& 120 & 155 & 327 & 4.3 \\
\hline
\end{tabular}




\section{References}

1. Crowley RK, Sherlock M, Agha A, Smith D, Thompson CJ. Clinical insights into adipsic diabetes insipidus; a large case series. Clinical Endocrinology 2007; 66: 475-82.

2. Ball SG, Vaidya B, Baylis PH. Hypothalamic adipsic syndrome; diagnosis and management. Clinical Endocrinology 1997; 47: 405-9.

3. Thompson CJ, Bland J, Bird J, Baylis PH. The osmotic thresholds for thirst and vasopressin release are similar in healthy men. Clinical Science 1986; 71: 651-66.

4. McKenna K. Osmoregulation in clinical disorders of thirst appreciation. Clinical Endocrinology 1998; 49: 139-52.

\section{W M H S Chandrasekara1', S Thondam ${ }^{1}$, M D Penney ${ }^{2}$ and L D K E Premawardhana ${ }^{1,3}$}

${ }^{1}$ Section of Endocrinology, Departments of Medicine and ${ }^{2}$ Chemical Pathology, Caerphilly Miners' Hospital, St. Martin's Road, Caerphilly, and ${ }^{3}$ Centre for Endocrine and Diabetes Sciences, University Hospital of Wales, Heath Park, Cardiff CF14 4 XN, UK.

Correspondence: WMHSC, e-mail <wasala.chandrasekara@nhs.net>. Received 28 November 2007 and revised version accepted 14 May 2008. Conflicts of interest: none declared. 